\title{
Meningkatkan Kualitas International Council for Small Business Melalui Pelatihan Pengelolaan Keuangan Dan Pelaporan Pajak
}

\author{
Ramlah Puji Astuti ${ }^{1 *}$, Moh. Yudi Mahadianto ${ }^{2}$, Ryana Noer Kholiazmi ${ }^{3}$ \\ Universitas Swadaya Gunung Jati Cirebon \\ e-mail:ramlah_astuti@yahoo.co.id \\ 2e-mail: mohyudim@yahoo.com \\ 3e-mail: ryananoerkholiazmi@gmail.com \\ *Corresponding Author
}

\begin{abstract}
ABSTRAK
Kegiatan program kreativitas mahasiswa ini memfokuskan pada pendampingan untuk pengurus International Council for Small Business (ICSB) dalam pelatihan membuat laporan keuangan untuk Usaha Mikro Kecil Menengah (UMKM) serta peningkatan kepatuhan pelaporan perpajakan bagi UMKM. Metode yang dilakukan dalam pendampingan adalah metode pendampingan secara daring yang melibatkan pengurus ICSB. Tahap awal dilakukan sosialisasi dan pelatihan kepada pengurus ICSB mengenai pelpaoran keuangan dan pelaporan pajak. Terakhir pengurus ICSB diberikan pendampingan dalam melakukan pelatihan kepada UMKM mengenai pelaporan keuangan dan pelaporan pajak. Hasil kegiatan pendampingan ini terlihat adanya peran aktif dari pengurus ICSB untuk melakukan pendampingan kepada UMKM dalam penyusunan laporan keuangan dan pelaporan pajak. Hasil pendampingan dari pegurus ICSB kepada UMKM dapat terlihat dari pelaku UMKM sudah mulai membuat catatan aktivitas keuangan selama beberapa minggu terakhir serta adanya peningkatan kepatuhan pajak dari UMKM seperti kemauan untuk membuat NPWP, membayar, dan melapor kan perpajakannya. Kegiatan ini memberikan dampak yang positif sehingga dapat direkomendasikan untuk kegiatan pendampingan selanjutnya dengan fokus yang lain.
\end{abstract}

Kata Kunci: UMKM; Laporan Keuangan; Laporan Perpajakan

\begin{abstract}
This student creativity program activity focuses on mentoring ICSB administrators in training in making financial reports for MSMEs and increasing tax reporting compliance for MSMEs. The method used in mentoring is an online mentoring method that involves ICSB administrators. The initial stage was carried out socialization and training to ICSB administrators regarding financial reporting and tax reporting. Finally, the ICSB management was given assistance in conducting training for MSMEs on financial reporting and tax reporting. The results of this assistance activity show the active role of the ICSB management to provide assistance to MSMEs in preparing financial reports and tax reporting. The results of assistance from ICSB administrators to MSMEs can be seen from the fact that MSME owners have started to make records of financial activities over the last few weeks as well as an increase in tax compliance from MSMEs such as the willingness to make NPWP, pay, and report their taxation. This activity has had a positive impact so that it can be recommended for further mentoring activities with other focuses.
\end{abstract}

Keywords: UMKM; Financial Reports; Tax Reports 


\section{PENDAHULUAN}

UMKM yang merupakan akronim dari Usaha Mikro Kecil Menengah adalah mata pencaharian yang belakangan ini banyak digeluti oleh masyarakat Indonesia. UMKM adalah usaha produktif yang dimiliki perorangan maupun badan usaha yang telah memenuhi kriteria sebagai usaha mikro. Dalam peraturan perundang-undangan No. 20 tahun 2008, sesuai pengertian UMKM tersebut maka kriteria UMKM dibedakan secara masing-masing meliputi usaha mikro, usaha kecil, dan usaha menengah. Dan juga menurut UU No. 20 pasal 3 Tahun 2008, UMKM bertujuan untuk menumbuhkan dan mengembangkan usaha dalam rangka membangun perekonomian nasional berdasarkan demokrasi ekonomi yang berkeadilan.

Pada tahun 2017, UMKM di Indonesia tercatat sebanyak 62.922.617 dan ditargetkan oleh Sekretaris Kementrian Koperasi dan Usaha Kecil dan Menengah pada 2019 akan meningkat sebanyak 5\% sejalan dengan pertumbuhan jumlah penduduk Indonesia. Pertumbuhan UMKM tersebut sangat berpengaruh besar dalam menopang pertumbuhan ekonomi Indonesia, dan menangani masalah perekonomian seperti pengangguran (Yusuf, et al., 2019) serta kemiskinan. Namun, UMKM di Indonesia masih mempunyai masalah dalam perkembangannya, contohnya yaitu pembiayaan modal, sumber daya manusia, pengetahuan masyarakat tentang pengelolaan keuangan (Rostiani, et al., 2021), pemasaran, dan tata cara membayar hingga melaporkan pajak khusus UMKM.

Pokok permasalahan berikutnya adalah para pelaku UMKM masih belum mengetahui kewajiban mereka sebagai warga negara Indonesia yaitu membayar pajak hingga pelaporan pajak. Sedangkan dalam APBN 2018, pendapatan negara dari sektor perpajakan mencapai 1.618,1 triliun rupiah dari keseluruhan pendapatan negara sebesar 1.894,7 triliun rupiah. Semakin maraknya pelaku UMKM di Indonesia diharapkan dapat meningkatkan pendapatan negara dengan kesadaran pajak yang dilakukan oleh para pelaku UMKM karena tidak semua pelaku UMKM sudah sadar akan kewajiban perpajakan yang berlaku.

Menurut Peraturan Pemerintah (PP) Republik Indonesia Nomor 46 Tahun 2013, PPh final untuk pajak UMKM adalah pajak atas penghasilan (omzet) dari usaha yang diterima atau diperoleh Wajib Pajak yang memiliki peredaran bruto dibawah Rp. 4,8M dalam setahun. Namun selanjutnya pemerintah mengeluarkan PP Nomor 23 Tahun 2018 mengenai tarif baru untuk PPh Final UMKM yang pada sebelumnya dikenakan tarif $1 \%$ dikurangi menjadi $0,5 \%$. Hal ini bertujuan untuk meningkatkan perekonomian negara dan minat usaha masyarakat dalam membangun UMKM. 
Permasalahan-permasalahan tersebut juga dirasakan oleh pelaku UMKM dalam naungan International Council for Small Business (ICSB) yang masih belum dapat mengelola keuangannya dengan baik dan sebagian masih belum mengetahui pelaporan pajak dan membayar pajak dengan baik.

Dalam rangka mengatasi permasalahan tersebut salah satu upaya yang dapat dilakukan adalah dengan melaksanakan pelatihan pengelolaan keuangan dan mendukung pelaporan pajak dengan tema "Meningkatkan Kualitas International Council for Small Business Melalui Pelatihan Pengelolaan Keuangan Dan Pelaporan Pajak”. Selain bertujuan untuk membuat laporan keuangan dan meningkatkan kesadaran pajak serta memberikan wawasan mengenai perkembangan usaha, kegiatan pendampingan maupun pelatihan menurut beberapa penelitian terdahulu (Syahrenny, 2019, Wijayanti, 2020, \& Darmawati, et al., 2020) mengungkapkan bahwa kegiatan mampu meningkatkan produktivitas UMKM agar dapat berkembang sesuai kebutuhan pasar.

\section{BAHAN DAN METODE}

Metode yang digunakan dalam kegiatan pemberdayaan kepada masyarakat ini adalah metode sistem tindakan dan pembelajaran yang partisipatif yang dikenal dengan PLA (Participatory Learning Action). Metode pengabdian masyarakat ini dikembangkan oleh Linda Mayoux tahun 2000-an (Sadia, 2013). Dengan metode PLA, proses dan evaluasi dilaksanakan secara partisipatif. PLA merupakan bentuk baru dari metode pengabdian masyarakat sebelumnya yang dikenal "learning by doing”. Secara singkat, PLA merupakan metoda pengabdian masyarakat yang terdiri dari proses belajar dari suatu topik, pengolahan, pemeliharaan, dan lain sebagainya setelah itu diikuti aksi atau kegiatan riil yang relevan dengan materi pengabdian masyarakat tersebut (Mardikanto, 2011). Namun dalam pelaksanaan pengabdian masyarakat kali ini berbeda dengan yang biasanya dilakukan, karena dengan adanya pandemi mengharuskan setiap individu untuk melakukan social distancing sehingga dalam pelaksanaannya dilakukan melalui media teknologi berupa aplikasi zoom meeting. Pelaksanaan pemberdayaan dilakukan dengan menggunakan beberapa tahap, yaitu sosialisasi mengenai pemahaman laporan keuangan UMKM, sosialisasi mengenai pemahaman perpajakan UMKM, pelatihan penyusunan laporan keuangan UMKM, pelatihan pelaporan perpajakan UMKM, dan pengenalan aplikasi APOSERBA. 
Program pemberdayaan ini juga menggunakan metode monitoring dan evaluasi. Tahap monitoring dan evaluasi dilakukan untuk melihat seberapa jauh program permberdayaan ini terlaksana dengan baik sesuai dengan target pencapaian kegiatan seperti yang direncankan. Kegiatan monitoring dan evaluasi dilakukan dengan indikator pencapaian tujuan dan tolak ukur sebagai berikut:

Tabel 1. Indikator Pencapaiaan Kegiatan

\begin{tabular}{|c|c|c|c|}
\hline No & Uraian Kegiatan & Target & Tolak ukur \\
\hline 1 & $\begin{array}{l}\text { Meningkatkan kemampuan pengurus ICSB untuk } \\
\text { dapat membina UMKM dalam melakukan } \\
\text { pencatatan setiap transaksi keuangan usahanya }\end{array}$ & & $\begin{array}{c}\text { Penyusunan buku } \\
\text { kas }\end{array}$ \\
\hline 2 & $\begin{array}{l}\text { Meningkatkan kemampuan pengurus ICSB untuk } \\
\text { dapat membina UMKM dalam membuat laporan } \\
\text { keuangan sederhana }\end{array}$ & 43 tenant & $\begin{array}{c}\text { Penyusunan } \\
\text { laporan keuangan }\end{array}$ \\
\hline 3 & $\begin{array}{l}\text { Meningkatkan kemampuan pengurus ICSB untuk } \\
\text { dapat membina UMKM dalam peningkatkan } \\
\text { kesadaran pelaku UMKM terhadap pelaporan pajak }\end{array}$ & 43 tenant & $\begin{array}{c}\text { Kesadaran } \\
\text { pentingnya pajak } \\
\text { bagi negara }\end{array}$ \\
\hline 4 & $\begin{array}{l}\text { Meningkatkan kemampuan pengurus ICSB untuk } \\
\text { dapat membina UMKM dalam peningkatkan } \\
\text { kepatuhan pelaku UMKM untuk membayar pajak }\end{array}$ & 43 tenant & $\begin{array}{c}\text { Kepatuhan } \\
\text { membayar pajak }\end{array}$ \\
\hline
\end{tabular}

Sumber: data primer diolah

\section{HASIL DAN PEMBAHASAN}

Program kegiatan pelatihan pelaporan keuangan dan perpajakan ini berlangsung selama 2 bulan. Pelatihan ini dimulai dengan memberikan sosialisasi mengenai pemahaman laporan keuangan dan perpajakan kepada pengurus ICSB yang telah bersedia untuk diberikan pelatihan secara intensif. Kegiatan ini dimulai pada bulan September sampai dengan Oktober 2020. Kegiatan dilaksanakan secara langsung dan berkala. Metode yang digunakan cukup efektif dilakukan karena penyampaian materi dilakukan hanya satu hari sisanya adalah pendampingan langsung ke pelaku UMKM yang berada didalam binaan ICSB. Kegiatan pendampingan dilakukan selama 2 bulan yaitu bulan September sampai dengan Oktober 2020. Secara umum kegiatan pendampingan yang dilakukan sebagai berikut : 
Tabel 2. Rangkuman Pelaksanaan Kegiatan Pendampingan

\begin{tabular}{|c|c|c|}
\hline Tahap awal & Tahap Kedua & Tahap Ketiga \\
\hline $\begin{array}{l}\text { 1. Sosialisasi mengenai } \\
\text { pemahaman laporan } \\
\text { keuangan UMKM }\end{array}$ & $\begin{array}{l}\text { 1. Pelatihan mengenai } \\
\text { penyusunan laporan } \\
\text { keuangan UMKM }\end{array}$ & 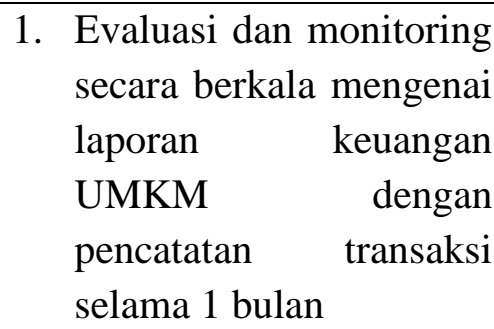 \\
\hline $\begin{array}{l}\text { 2. Sosialisasi mengenai } \\
\text { pemahaman } \\
\text { perpajakan UMKM }\end{array}$ & $\begin{array}{l}\text { 2. Pelatihan } \\
\text { pelaporan } \\
\text { UMKM }\end{array}$ & $\begin{array}{l}\text { 2. Memberikan pengarahan } \\
\text { kepada UMKM untuk } \\
\text { membuat laporan } \\
\text { keuangan secara berkala }\end{array}$ \\
\hline & $\begin{array}{l}\text { 3. Pengenalan } \\
\text { aposerba }\end{array}$ & \\
\hline
\end{tabular}

Keberhasilan program pelatihan pelaporan keuangan dan perpajakan dapat dilihat pada setiap pemberian materi dilakukan evaluasi dan monitoring. Hal ini bertujuan untuk melihat perubahan perilaku pengurus ICSB terhadap materi yang diberikan. Proses evaluasi dengan melihat kondisi awal, saat pendapingan, dan setelah pendampingan. Adapun Matrik Evaluasi Kegiatan Program Pendampingan Pengembangan UMKM dapat dilihat pada tabel berikut :

Tabel 3. Matrik Pendampingan UMKM Kota Cirebon

\begin{tabular}{|c|c|c|c|c|}
\hline No. & Materi & Kondisi Awal & $\begin{array}{l}\text { Pada Saat } \\
\text { Pendampingan }\end{array}$ & $\begin{array}{l}\text { Setelah } \\
\text { Pendampingan }\end{array}$ \\
\hline 1 & $\begin{array}{l}\text { Sosialisasi } \\
\text { pentingnya } \\
\text { laporan } \\
\text { keuangan } \\
\text { bagi } \\
\text { UMKM }\end{array}$ & 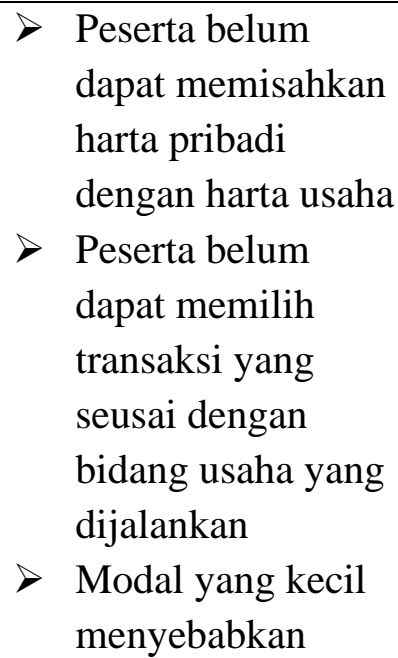 & $\begin{array}{l}>\text { Peserta antusisas } \\
\text { mendengarkan } \\
\text { penyampaian materi } \\
>\text { Peserta mulai } \\
\text { terbuka wawsanya } \\
\text { mengenai transaksi } \\
\text { keuangan dalam } \\
\text { dunia usaha } \\
>\text { peserta memberikan } \\
\text { pertanyaan sesuai } \\
\text { contoh usaha yang } \\
\text { dijalankan }\end{array}$ & $\begin{array}{l}\text { Peserta menyadari } \\
\text { pentingnya } \\
\text { memishkan } \\
\text { keungan usaha } \\
\text { dengan keuangan } \\
\text { pribadi } \\
>\text { Peserta sudah } \\
\text { dapat memahami } \\
\text { tujuan pembuatan } \\
\text { laporan keuangan } \\
>\text { Peserta sudah } \\
\text { dapat memahami }\end{array}$ \\
\hline
\end{tabular}




\begin{tabular}{|c|c|c|c|c|}
\hline No. & Materi & Kondisi Awal & $\begin{array}{l}\text { Pada Saat } \\
\text { Pendampingan }\end{array}$ & $\begin{array}{l}\text { Setelah } \\
\text { Pendampingan }\end{array}$ \\
\hline & & $\begin{array}{l}\text { peserta masih } \\
\text { meyatukan } \\
\text { pengeluaran untuk } \\
\text { pribadi dengan } \\
\text { pengeluaran usaha } \\
>\text { Peserta belum } \\
\text { dapat memahami } \\
\text { sistem transaski } \\
\text { keungan usaha }\end{array}$ & $\begin{array}{l}\text { peserta mulai } \\
\text { memahami manfaat } \\
\text { dari pembuatan } \\
\text { laporan keuangan } \\
\text { usahanya }\end{array}$ & $\begin{array}{l}\text { pentingnya } \\
\text { membuat laporan } \\
\text { keuangn bagi } \\
\text { usahanya } \\
>\text { Peserta ingin } \\
\text { segera melakukan } \\
\text { pencatatan } \\
\text { laporan keuangan }\end{array}$ \\
\hline 2 & $\begin{array}{l}\text { Sosialisasi } \\
\text { Perpajakan } \\
\text { UMKM }\end{array}$ & $\begin{array}{l}\text { Peserta tidak } \\
\text { memiliki } \\
\text { pengentahuan } \\
\text { terkait perpajakaan } \\
>\text { Peserta tidak } \\
\text { mengetahui } \\
\text { peraturan } \\
\text { mengenai pajak } \\
\text { UMKM yang } \\
\text { berlaku di } \\
\text { Indonesia } \\
\text { Peserta kurang } \\
\text { menyadari } \\
\text { pentingnya pajak } \\
\text { bagi pembangunan } \\
\text { negara }\end{array}$ & $\begin{aligned} & \text { Peserta sedikit } \\
& \text { paham tentang } \text { peraturan pajak } \\
& \text { yang berlaku bagi } \text { UMKM } \\
& \text { Persrta antusias } \\
& \text { memahami materi } \text { yang disampaikan } \\
&> \text { Peserta banyak } \\
& \text { memberikan } \text { pertanyaan terkait } \\
& \text { perpajakan di } \\
& \text { Indonesia } \\
& \text { Peserta } \\
& \text { memberikan contoh } \\
& \text { kasus pengenaan } \\
& \text { tarif pajak untuk } \\
& \text { UMKM }\end{aligned}$ & $\begin{array}{l}\text { Peserta } \\
\text { mempunyai } \\
\text { pandangan yang } \\
\text { berbeda mengenai } \\
\text { sistem perpajakan } \\
\text { di Indonesia } \\
>\text { Peningkatan } \\
\text { kepatuhan } \\
\text { perpajakan } \\
\text { dikalangan } \\
\text { peserta UMKM } \\
>\text { Peserta dapat } \\
\text { menghitung dasar } \\
\text { pengenaan pajak } \\
\text { bagi UMKM }\end{array}$ \\
\hline 3 & $\begin{array}{l}\text { Pelatihan } \\
\text { penyusunan } \\
\text { laporan } \\
\text { keuangan } \\
\text { UMKM }\end{array}$ & $\begin{array}{l}\text { Peserta masih } \\
\text { belum dapat } \\
\text { memisahkan } \\
\text { keuangan pribadi } \\
\text { dengan keuangan } \\
\text { usaha } \\
>\text { Peserta belum } \\
\text { mencatata seluruh } \\
\text { transaksi keungan } \\
\text { yang dilakukan } \\
\text { setiap harinya }\end{array}$ & $\begin{array}{l}\text { Menjelaskan terkait } \\
\text { definisi transaksi, } \\
\text { mengidentifikasi } \\
\text { jenis transaksi dan } \\
\text { contoh dari jenis } \\
\text { transaksi. } \\
\text { Menjelaskan } \\
\text { aktivitas keungan } \\
\text { yang biasa dilakukan } \\
\text { beserta contohnya }\end{array}$ & $\begin{array}{l}>\text { Peserta dapat } \\
\text { memhami } \\
\text { pentingnya } \\
\text { pencatatan } \\
\text { transaksi } \\
\text { keuangan. } \\
>\text { Peserta memahami } \\
\text { jenis- jenis akun } \\
\text { dalam pembukuan } \\
\text { akuntasi. }\end{array}$ \\
\hline
\end{tabular}




\begin{tabular}{|c|c|c|c|}
\hline Materi & Kondisi Awal & $\begin{array}{l}\text { Pada Saat } \\
\text { Pendampingan }\end{array}$ & $\begin{array}{l}\text { Setelah } \\
\text { Pendampingan }\end{array}$ \\
\hline & $\begin{array}{l}\text { Peserta belum } \\
\text { menyadari } \\
\text { pentingnya } \\
\text { pengumpulan bukti } \\
\text { transaksi keuangan } \\
\text { untuk kegiatan } \\
\text { usahanya } \\
>\text { Peserta belum dapat } \\
\text { mengidentifikasi } \\
\text { setiap transaksi } \\
\text { yang terjadi dari } \\
\text { aktivitas usahanya } \\
\text { Peserta belum bisa } \\
\text { menganalisis jenis } \\
\text { transaksi dan } \\
\text { berdasarkan sistem } \\
\text { pembukuan } \\
\text { akuntansi dasr } \\
\text { persamaan } \\
\text { akuntansi. }\end{array}$ & $\begin{array}{l}\text { Menjelaskan definisi } \\
\text { akun, } \\
\text { mengidentifikasi } \\
\text { jenis akun, } \\
\text { mengelompokkan } \\
\text { jenis akun dan } \\
\text { contohnya. } \\
\text { Menjelaskan terkait } \\
\text { persamaan dasar } \\
\text { akuntansi } \\
>\text { Praktek melakukan } \\
\text { pencatatan akuntansi } \\
\text { berdasarkan akun, } \\
\text { sesuai dengan jenis } \\
\text { usaha masing-masing } \\
\text { peserta. }\end{array}$ & $\begin{array}{l}\text { Peserta mulai } \\
\text { melakukan } \\
\text { pencatatan } \\
\text { kedalam } \\
\text { pembukuan dari } \\
\text { setiap aktivitas } \\
\text { transaksi yang } \\
\text { dilakukan. } \\
\text { Peserta dapat } \\
\text { mengidentifikasi } \\
\text { jenis transaksi } \\
\text { sesuai dengan jenis } \\
\text { usahanya masing- } \\
\text { masing bisa } \\
\text { Peserta bisa } \\
\text { melakukan } \\
\text { praktek persamaan } \\
\text { dasar akuntansi } \\
\text { Peserta } \\
\text { mengelompokkan } \\
\text { transaksi } \\
\text { usahanya masing- } \\
\text { masing } \\
\text { berdasarkan akun }\end{array}$ \\
\hline
\end{tabular}

Sumber : data primer diolah

\section{KESIMPULAN DAN SARAN}

Pelaksanaan kegiatan pendampingan pengembangan laporan keuangan dan pelaporan pajak yang termasuk ke dalam International Council For Small Bussiness (ICSB), memberikan memberikan banyak manfaat untuk pelaku UMKM diantaranya Pelaku UMKM berhasil meningkat kesadaranya akan pelaporan pajak bagi UMKM dan pentingnya Pajak bagi pembangunan negara. Kepatuhan pelaporan pajak meningkat setelah mengikuti sosialisasi dan pelatihan ini. 
Dapat meningkatkan potensi usaha pelaku UMKM melalui perencanaan keuangan yang baik serta pelaporan keuangan yang tertib dan terstruktur. Sehingga mudah dimengerti oleh investor dan kreditor. Pengurus ICSB berhasil meningkatkan kesadaran pelaku UMKM akan pelaporan pajak bagi UMKM dan pentingnya pajak bagi pembangunan negara. Kepatuhan pelaporan pajak meningkat setelah mengikuti sosialisasi dan pelatihan ini, dan sudah dapat membantu pelaku UMKM memisahkan kegiatan usahanya dengan pengeluaran pribadinya. Sehingga peningkatan kapasitas produksi dapat ditingkat. Tujuan utamanya adalah peningkatan omzet penjualan produk mereka. Sehingga akan berdampak pada peningkatan pemasukan pajak bagi negara

Adapun saran kegiatan Pelatihan Penyusunan Laporan Keuangan dan Pelaporan Pajak bagi pengurus ICSB, yaitu: dibutuhkan program lanjutan secara kontinyu sehingga mengarah pada peningkatan kapasitas pengurus ICSB dalam membantu pelaku UMKM baik dalam bentuk produk maupun kemasan, serta fasilitasi promosi melalui pameran tingkat Kabupaten, Provinsi, maupun nasional. Diperlukan dukungan dari semua stakeholder untuk mensosialisasikan setiap peraturan perpajakan yang berlaku sehingga masyarakat dapat mengetahuinya. Perlu dihasilkan program pengembangan untuk pengurus ICSB dalam membantu pelaku UMKM melalui teknologi informasi dengan didukung oleh pelaporan keuangan berbasis digital sesuai dengan perkembangan jaman.

\section{UCAPAN TERIMA KASIH}

Terima kasih kami sampaikan kepada Direktorat Pembelajaran dan Kemahasiswaan Direktorat Jenderal Pendidikan Kementrian Pendidikan dan Kebudayaan, Universitas Sawadaya Gunung Jati Cirebon yang telah memberikan bantuan baik moril maupun materil atas terselenggaranya kegiatan Pengabdian kepada masyarakat. Terima kasih kami ucapkan kepada Dekan Fakultas Ekonomi yang telah memberikan banyak motivasi dan dorongan kepada kami untuk terus memberikan pengabdian kepada masyarakat. Ucapan terima kasih kami sampaikan kepada kepada pengurus International Council for Small Bussiness (ICSB) kota Cirebon yang telah memberikan bantuan untuk suksesnya kegiatan pengabdian ini. Tak lupa kami sampaikan banyak terima kasih kepada mitra UMKM yang tergabung dalam kelompok binaan ICSB yang telah bersedia menjadi peserta dalam kegiatan pengabdian kali ini. Semoga program pengabdian ini dapat memberikan manfaat dan keberkahan bagi semua pihak. 


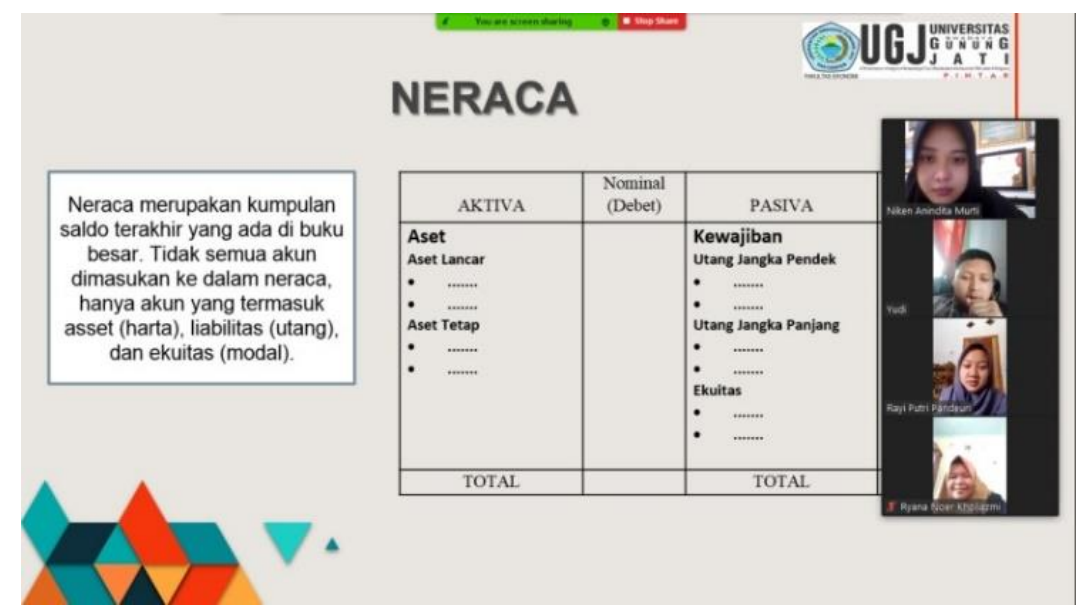

Gambar 1. Pertemuan daring membahas laporan keuangan

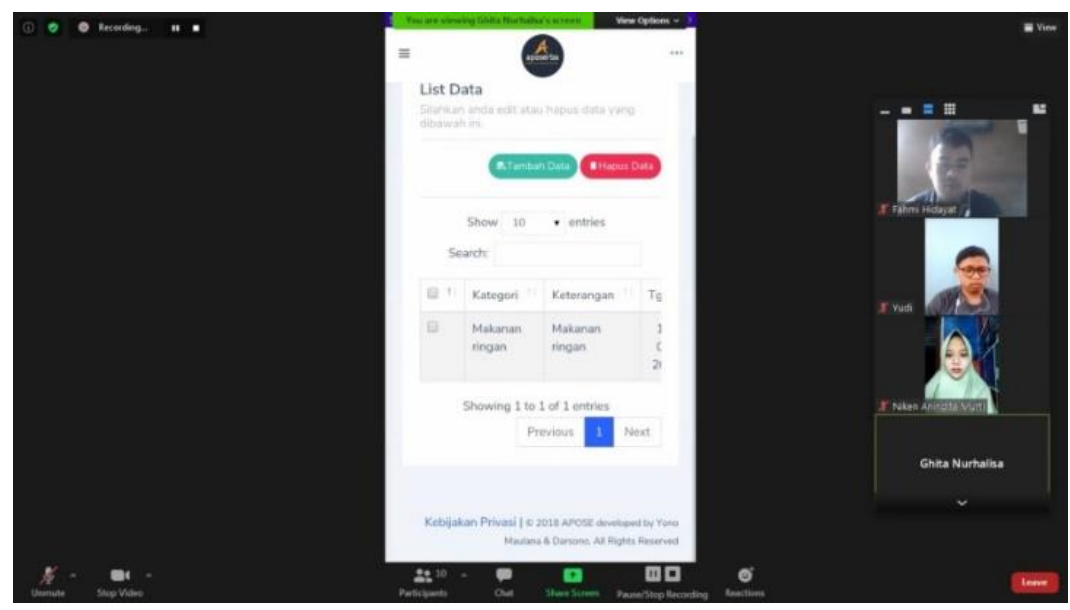

Gambar 2. Pertemuan daring membahas aplikasi kasir online

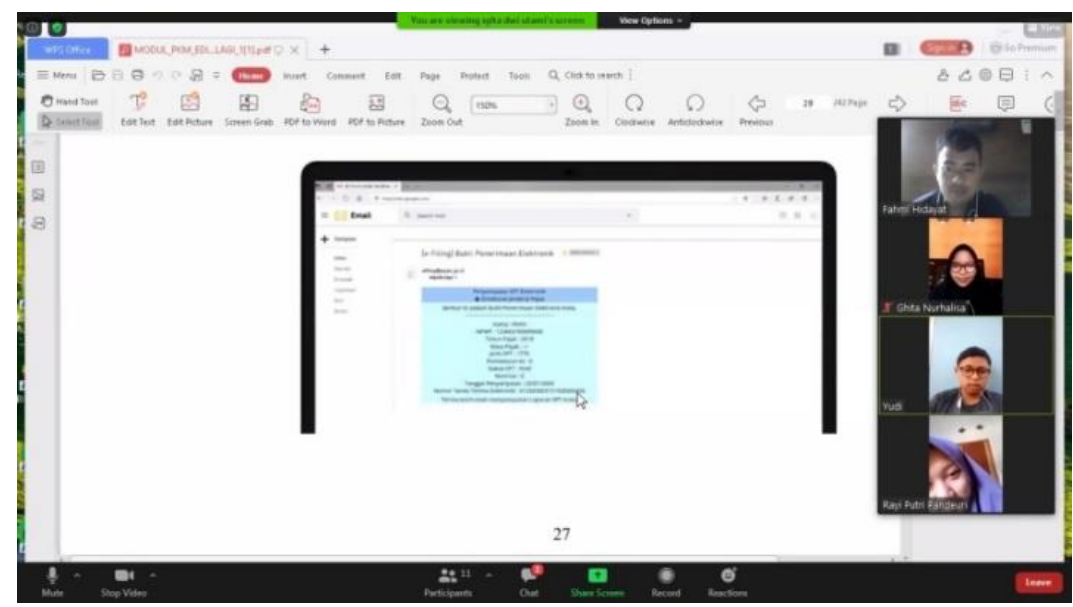

Gambar 3. Pertemuan daring membahas mengenai cara pelaporan pajak 


\section{DAFTAR PUSTAKA}

Darmawati, D., Dizar, S., \& Harahap, C. D. (2020). Peningkatan Efektivitas Penyusunan Laporan Keuangan Sederhana Bagi Himpunan Pengusaha Laundry Indonesia (Hipli). Jurnal Berdaya Mandiri, 2(2), 366-375. https://doi.org/10.31316/jbm.v2i2.696

Data Statistik Kementrian Koperasi dan UKM

Direktorat Pembelajaran dan Kemahasiswaan. (2020) Adendum Pedoman Program Kreativitas Mahasiswa PKM 5 Bidang tahun 2020

Mardikanto, T. (2011). Pemberdayaan Masyarakat. UNS Press.

Muizu, Wa Ode Zusnita. 2017. "Pendampingan Pengelolaan Umkm Di Kecamatan Talun Kabupaten Cirebon-Jawa Barat.” Prosiding Seminar Hasil Pengabdian Kepada Masyarakat (SNP2M) 2017 (pp.100-103) 2017: 100-103.

Peraturan Pemerintah (PP) Nomer 23 Tahun 2018 tentang Pajak Penghasilan atas Penghasilan yang diterima atau diperoleh Wajib Pajak yang Memiliki Peredaraan Bruto Tertentu

Peraturan Pemerintah (PP) Nomer 46 Tahun 2013 tentang Pajak Penghasilan atas Penghasilan yang diterima atau diperoleh Wajib Pajak yang Memiliki Peredaraan Bruto Tertentu

Rostansi, Y., Indaryono. Yusuf, A. M., Apdian, Donny. 2021. Pelatihan Penyusunan Laporan Keuangan Untuk UMKM Kabupaten Karawang. Abdimas: Sistem dan Teknologi Informasi, 1(1). 1-6.

Sadia, I. W. (2013). Laporan Akhir ibW Mutigunua dan Pedahan.

Sriyana, Jaka. 2010. Strategi Pengembangan Usaha Kecil Dan Menengah (UMKM): Studi Kasus Di Kabupaten Bantul Paper pada Simposium Nasional 2010: Menuju Purworejo Dinamis dan Kreatif

Syahrenny, N. (2019). Laporan Keuangan UMKM Sesuai Sak Emkm Nenny Syahrenny. Seminar Nasional Penelitian Dan Pengabdian Masyarakat, 13-17.

Wijayanti, R. (2020). Pelatihan Penyusunan Laporan Keuangan pada Usaha Dagang Sahadewa Batik. Proceeding of The URECOL, (2012), 112-116.

Yusuf, A. A., Saefullah, Eef., Fitriya. (2019). Peran Kelompok Usaha Emping Melinjo Dalam Meningkatkan Kesejahteraan Ekonomi Masyarakat (Studi Kasus Di Desa Tuk Kecamatan Kedawung Cirebon). DIMASEJATI: Jurnal Pengabdian kepada Masyarakat, 1(1), 52-63. 